\title{
A NATUREZA JURÍDICA DO BITCOIN NO ORDENAMENTO JURÍDICO BRASILEIRO
}

\author{
Marcelo Markus Teixeira ${ }^{1}$ \\ Universidade Comunitária da Região de Chapecó (Unochapecó) \\ Matheus Detoni ${ }^{2}$ \\ Universidade Comunitária da Região de Chapecó (Unochapecó)
}

\section{Resumo}

Este trabalho tem como tema o bitcoin, tecnologia surgida em 2009, que reconfigurou as premissas centenárias acerca do conceito de moeda e que possibilita a realização de negócios de maneira segura e dissociada de vínculo direto com qualquer Estado. A relevância e atualidade do presente tema são atestadas pelos debates acerca de sua natureza jurídica nos mais diversos ordenamentos jurídicos estatais, já que seus usuários a consideram de diversas maneiras, desde nova forma de moeda e novo sistema de pagamento ou transferência de fundos, até mesmo como bem ou commodity. Diante deste cenário, o presente trabalho tem como objetivo analisar a natureza jurídica do bitcoin dentro do ordenamento jurídico brasileiro, verificando como o direito brasileiro classifica o instituto momentaneamente. A pesquisa está ancorada no método dedutivo e é exercida por meio de análise de fontes literárias e normativas. Ao final conclui-se que o bitcoin possui algumas características definidas sendo, portanto, classificável no Brasil como bem imaterial e móvel. Alternativamente, seria possível sua classificaçáo como commodity. Contudo, tal impasse somente será resolvido com a regulamentação do instituto no Brasil.

Palavras-chave: bitcoin; criptomoedas; moedas; ordenamento jurídico.

1 Doutor em Direito Internacional Privado pela Universität zu Köln, com título revalidado no Brasil pela Universidade de São Paulo (USP) e pela Universidade Federal de Santa Catarina (UFSC). Mestre em Direito Internacional Privado pela Universität zu Köln. Mestre em Direito e Política da Uniăo Europeia pela Università degli Studi di Padova. Graduado em Ciências Jurídicas pela Universidade do Vale do Itajaí (Univali). Professor do programa de Mestrado Acadêmico em Direito da Unochapecó. ORCID: http://orcid.org/0000-0003-1630-1660 / e-mail: marcelomarkus@unochapeco.edu.br

2 Bacharel em Direito pela Unochapecó e advogado. e-mail: matheusdetoni@unochapeco.edu.br 


\section{THE LEGAL NATURE OF BITCOIN IN THE BRAZILIAN LEGAL ORDER}

\section{Abstract}

This article has as subject the Bitcoin, a technology that emerged in 2009, which reconfigured the centenary premises about the concept of currency and that makes it possible to conduct business in a safe and dissociated way from a direct link with any state. The relevance and timeliness of the present theme is attested by the debates about its legal nature in the most diverse state legal systems, since its users consider it in several ways, from a new form of currency and a new system of payment or transfer of funds, even as good or commodity. Given this scenario, this article aims to analyze the legal nature of bitcoin within the Brazilian legal system, verifying how Brazilian law classifies the institute at the moment. The research is based in the deductive method and is carried out through the analysis of literary and normative sources. In the end it is concluded that bitcoin has some definite characteristics and is therefore classifiable in Brazil as immaterial and mobile good. Alternatively, it could be classified as a commodity. However, this impasse will only be resolved with the regulation of the institute in Brazil.

Keywords: bitcoin; cryptocurrency; currency; legal order. 


\section{Introdução}

O mundo do Direito é amplo, de modo que os fatos sociais abrangidos por ele são numerosos. Com o passar dos anos, tecnologias são criadas, atualizadas e modificadas, e em algum momento, essas inovaçóes vão de encontro ao campo jurídico, surgindo normas a fim de regular as relaçóes provenientes de novos contextos.

Nas últimas décadas, com o aprimoramento e a atualização da tecnologia, novidades como os buscadores e celulares com alta capacidade de processamento modificaram o modo de acesso a informaçóes, tornando tudo mais rápido e prático. Nessa esteira, surgiu, em 2009, o blockchain, uma tecnologia revolucionária.

O blockchain pode ser descrito como um livro-caixa que tem a capacidade de armazenar informaçóes em blocos dispostos em cadeia, recurso que dificulta a modificação ou exclusão das informaçôes. Por isso, os registros são guardados com extrema segurança. Diante disso, surge um desafio para o Direito, pois com a chegada do blockchain, foram criadas as criptomoedas (ou moedas digitais), que passaram a circular por diversos países, sendo utilizadas como meio de pagamento e representando uma nova espécie de moeda ou uma espécie de commodity para investidores especularem nos mercados de bitcoins. Em meio a esse turbilhão de novidades, surge o desafio de regulamentar algo que transcende as fronteiras brasileiras, de maneira decentralizada e global.

Apesar da amplitude e da quantidade de normas, o Direito é incapaz de prever todas as relaçôes humanas com consequências jurídicas e, de tempos em tempos, depara-se com grandes desafios para atualizar-se. Como o que surge nesse complexo cenário, que requer a definição da natureza jurídica das criptomoedas, com a tarefa de regular essa inovação.

$\mathrm{Na}$ busca pelas respostas para esse fenômeno, dicutem-se elementos que possam determinar a natureza jurídica das criptomoedas, tendo como principal referencial o ordenamento jurídico brasileiro, ainda que esse não tenha regulamentação específica.

\section{Bitcoin}

O bitcoin é um conjunto de conceitos e tecnologias que formam a base de um ecossistema de dinheiro digital, ou moeda digital, sendo que as unidades de moedas são chamadas de bitcoins (ANTONOPOULOS, 2016). Como essas moedas e seu controle se propóem descentralizados, ela funciona por meio de uma rede, ponto a ponto, consistindo em um sistema de pagamento global (ULRICH, 2014). 
Como a rede é descentralizada, ela se diferencia, principalmente, por não depender de serviços de terceiros ou intermediários (como PayPal ou Mastercard) para ligar uma pessoa a outra em suas transaçóes financeiras. $\mathrm{O}$ bitcoin eliminou pela primeira vez o problema do gasto duplo, falha que possibilitava que um usuário de moedas digitais gastasse mais de uma vez a mesma moeda digital armazenada em seu computador. Esse problema foi superado usando o blockchain que também dispensa a necessidade de um terceiro ao empregar um registro histórico de transaçóes. (ULRICH, 2014).

Medeiros (2017) define o bitcoin como uma espécie de dinheiro digital, utilizado virtualmente por meio de computadores e dispositivos móveis, como smartphones e tablets, e transacionado e transferido diretamente pela Internet, de maneira descentralizada. Seu principal objetivo seria tornar-se uma moeda mundial no futuro, substituindo as demais moedas de referência. Diferentemente do dinheiro físico, os bitcoins são registrados em carteiras virtuais que, na verdade, são aplicativos que rodam em dispositivos móveis e computadores.

Cada usuário de bitcoin possui chaves que lhes permitem comprovar essas transaçóes na rede bitcoin. Essas chaves são guardadas em carteiras digitais ou no próprio computador do usuário. Com a posse dessas chaves, os usuários podem transferir bitcoins por meio da rede, realizando as mesmas transaçóes que seriam realizadas com moedas, incluindo compra e venda de bens, envio de dinheiro a pessoas ou organizações, ou mesmo extensão de crédito. Além disso, os bitcoins podem ser comprados, vendidos ou trocados por outras moedas em casas de câmbio especializadas, o que o torna, entâo, um dinheiro perfeito para a Internet, uma vez que é rápido, seguro e destituído de fronteiras (ANTONOPOULOS, 2016). Isso, segundo Ulrich (2014, p. 18), faz do bitcoin "não apenas uma rede de pagamento descentralizada, mas também uma moeda virtual".

Portanto, o bitcoin é, basicamente, a junção de duas tecnologias: (i) a distribuição de um banco de dados por meio de uma rede ponto a ponto; e (ii) a criptografia, que, ao contrário das redes usuais (redes em que existe um servidor central com computadores conectados a elas), são ligadas em rede ponto a ponto, sem que haja um servidor central. Nessa arquitetura de rede, cada um dos pontos - ou nós - da rede funciona tanto como cliente, quanto como servidor, sendo todos iguais, o que possibilita o compartilhamento de dados sem a necessidade de um servidor central. Sendo assim, a rede ponto a ponto é uma rede descentralizada e com força computacional distribuída (ULRICH, 2014). 


\section{$2 \mathrm{O}$ renascimento do dinheiro}

O surgimento do bitcoin como uma moeda digital acompanha algumas dúvidas, e uma delas - talvez a principal - é se essas moedas virtuais poderiam ser consideradas dinheiro ou se essa inovação seria apenas um sistema de pagamentos ou transferência de fundos. Pode uma unidade de bitcoin, algo que não existe no mundo físico, ser considerado um bem? Será que existe um valor de troca em uma moeda virtual? Qual seria o lastro do bitcoin? (ULRICH, 2014).

$\mathrm{O}$ que se sabe é que o ser humano atua para alcançar seus objetivos, empregando meios próprios a fim de conseguir o desejado. Satoshi Nakamoto ${ }^{3}$ inventou o bitcoin, que foi progredindo, e outros usuários passaram a utilizá-lo com os mais diversos objetivos - uns com interesse na criptografia, outros, para protestar contra o sistema financeiro. No início de 2009, os bitcoins eram considerados simples mercadorias virtuais ou bens econômicos. Então, os bitcoins foram valorados pelos indivíduos que os adquiriram (ULRICH, 2014).

O bitcoin nasceu em janeiro de 2009 e, alguns meses depois, deixou de ser adquirido como meio de troca, para passar a satisfazer necessidades individuais, acarretando certo valor de uso (ULRICH, 2014). O mais importante é que houve uma real demanda por bitcoins, com consequente valorizaçáo da moeda, pela busca desta enquanto mercadoria. Esse caminho percorrido pelo bitcoin foi sendo percebido por alguns indivíduos, que passaram a empregá-lo como meio de troca, embora menos líquido que as moedas que utilizamos no dia a dia (ULRICH, 2014).

Conforme Ulrich (2014, p. 54) explica, "a primeira transação de que se tem notícia se deu em maio de 2010, quando 'laszlo' trocou uma pizza por $10 \mathrm{mil}$ bitcoins - em retrospecto, poderia ter sido a pizza mais cara do mundo". Segundo o autor, desde então, os bitcoins tornaram-se meio de troca, em consonância com seu objetivo fundamental. Para ele, estaríamos potencialmente testemunhando, em tempo real, o nascimento de uma moeda, com documentação disponível para qualquer investigação por parte de economistas (ULRICH, 2014).

Assim, percebe-se que é difícil definir bitcoin, embora ele apresente algumas características de moeda. Para Ulrich (2014, p. 63), "são elencados três elementos principais que influenciam na escolha de uma moeda: liquidez, reserva de valor e custos de transação". A maior desvantagem do bitcoin em relação às demais moedas é a liquidez, mas isso tende a diminuir conforme mais pessoas e empresas aceitarem transaçóes com bitcoin.

Essa nova forma de dinheiro promove uma grande redução de custos de

3 Satoshi Nakamoto é um pseudônimo utilizado pela pessoa (ou pessoas) responsáveis pela criação do bitcoin. 
transação, desconhecendo também fronteiras políticas, tornando possível enviar e receber bitcoins de qualquer lugar do mundo, sem que seja necessário realizar solicitaçôes a gerentes de banco, assinar documentos ou comparecer a agências bancárias ou caixas eletrônicos, as transaçôes são feitas com a mesma facilidade com a qual se envia um e-mail, sem a preocupação de guardá-lo em algum armazém ou banco (ULRICH, 2014).

Portanto, é plenamente possível que, com o passar do tempo, o bitcoin venha a superar tanto as moedas fiduciárias quanto valores em metais, como ouro e prata (como meio de troca), para finalmente se tornar dinheiro. Isso, no entanto, ainda depende da ampliação da aceitaçấo do bitcoin como moeda (ULRICH, 2014).

Durante um bom tempo ao longo da história, a moeda escolhida por excelência foi o ouro, sendo o principal ativo utilizado como lastro pelos bancos, uma vez que os certificados de depósitos, bilhetes de bancos ou depósitos já eram meras representaçôes da moeda propriamente dita. Esses substitutos monetários sempre foram aceitos como se fossem moeda, em razão da possibilidade de conversão em espécie quando solicitado ao banco. Todavia, com a consagração do sistema bancário nos últimos dois séculos, o lastro em ouro foi modificado e os governos inflacionaram a oferta de bilhetes, promovendo a depreciação do valor de mercado. Assim, o ouro circula cada vez menos na economia com os intercâmbios no mercado acontecendo, em sua maior parte, por meio dos papel-moeda. Logo, é melhor para o Governo remover qualquer vínculo ou lastro ao ouro para poder emitir moeda sem qualquer tipo de restrição (ULRICH, 2014).

Portanto, para Ulrich (2014, p. 73), o "lastro não é uma necessidade teórica de uma moeda, apenas uma tecnicalidade empírica cujo principal serviço foi o de servir como restrição às práticas imprudentes de banqueiros e às investidas inflacionistas do Estado".

\section{Funçóes da moeda}

A moeda tem várias funçóes, e a principal delas é ser um meio de pagamento. Sendo a moeda um ativo, ela pode ser empregada na troca de bens e serviços ou em operaçóes de compra e venda. Para que isso aconteça, é essencial que a moeda seja amplamente aceita e que todos os agentes tenham confiança. Existe uma diferença entre meio de troca e meio de pagamento, sendo meio de troca quando um cartão de crédito é utilizado e a transação não é acompanhada por uma transferência de riqueza, já que a venda foi a prazo. Portanto, o cartão de crédito é um meio de troca, e não um meio de pagamento, pois o pagamento final será efetuado no futuro, quando a fatura for paga (SANT'ANA, 1997). 
Nesse raciocínio, entende-se que o uso da moeda viabiliza o funcionamento de toda a economia, desempenhando, de acordo com Assaf Neto (2001), quatro importantes funçôes:

1. Meio de troca, promovendo o intercâmbio de bens e serviços, em substituição ao antigo escambo.

2. Divisibilidade, a qual permite a negociação de partes ou fraçóes dos bens e serviços. Essa característica imprime maior agilidade às transaçóes de mercado, otimizando todas as atividades econômicas.

3. Reserva de valor, permitindo que os agentes econômicos mantenham seus patrimônios para uso posterior. Essa função faz que a moeda apresente liquidez absoluta, possibilitando sua conversão imediata em qualquer ativo. Essa capacidade traduz uma maneira alternativa de guardar riquezas, e essa função não é exercida exclusivamente pela moeda, existindo outras formas de ativos financeiros e não financeiros (ROSSETTI, 2011).

Todas essas características verificam-se igualmente no bitcoin.

Portanto, a moeda, como reserva de valor, proporciona ao indivíduo a opçáo de utilizá-la ou guardá-la para uso posterior, de acordo com sua necessidade. Rossetti (2011, p. 22) destaca "a pronta e imediata aceitação da moeda, quando da decisão de convertê-la em outros ativos, financeiros ou reais. A essa aceitaçáo adiciona-se particularmente de ser a moeda um ativo conversível em ampla área geográfica”, o que permite a separação entre compra e venda de bens e serviços; logo, a moeda suprime a exigência de dupla coincidência de desejos (BERCHIELLI, 2000), propiciando uma economia de trocas diretas, uma economia monetária em que o processo se altera, com bens sendo trocados por moedas e moedas sendo trocadas por bens (STANFORD, 1981).

Outra função da moeda é a capacidade de distribuir pagamentos ao longo do tempo, pois representa uma medida referencial de valor, sendo garantida pelo Estado. Isso possibilita um planejamento de longo prazo. Graças a essa propriedade é que existe o crédito, ou seja, a possibilidade de saldar, no futuro, dívidas contraídas no presente (BERCHIELLI, 2000). O bitcoin, por sua vez, não é garantido pelo Estado, além de não ter a capacidade de distribuir pagamentos na função de crédito, o que dificulta ao bitcoin encaixar-se perfeitamente como uma moeda. Porém, existem inúmeras características que apontam similaridades do bitcoin com uma moeda.

Uma moeda está destinada a circular por um longo tempo, não podendo ser facilmente deteriorável. Essa caraterística garante satisfatoriamente a função da moeda como reserva de valor, além de permitir a subdivisão sem perda, possibilitando a realização de grandes e pequenas transaçóes (BERCHIELLI, 2000). 
A riqueza pode ser conservada, e as vantagens incluem a eliminação dos custos com estocagem e deterioração, bem como a conveniência da conservação de um ativo líquido (STANFORD, 1973). Existem outros ativos que não apresentam liquidez total, tais como certificados de depósitos bancários, que não são títulos de aceitação imediata por todos, mas têm liquidez parcial, e por isso são considerados “quase-moeda" (MARINHO, 1996, p. 8).

\section{Dos bens}

Como não é possível determinar com exatidão se o bitcoin é uma moeda ou, talvez, um bem, é imperioso que conheçamos, também, as características dos bens.

Em um sentido filosófico, um bem é tudo o que satisfaz uma necessidade humana, já num sentido jurídico o conceito de coisas corresponde ao de bens, mas nem sempre há perfeita sincronização entre as duas expressôes. "Às vezes, coisas são o gênero e bens, a espécie, outras vezes, estes são o gênero e aquelas, a espécie; outras, finalmente, são os dois termos usados como sinônimos, havendo entre eles coincidência de significação" (GONÇALVES, 2011). Assim, cada classificação baseia-se em uma característica peculiar dos bens, sendo possível encaixá-los em várias categorias (DINIZ, 2013). No estudo da natureza jurídica do bitcoin, os bens que poderiam ser relacionados seráo apresentados e comparados.

Beviláqua (1908 apud GONÇALVES, 2011, p. 276) define bens como "valores materiais ou imateriais que servem de objeto a uma relação jurídica”. Isso relaciona o bitcoin como um bem imaterial. Além disso, Gonçalves (2011, p. 276) esclarece que "bens são coisas que por serem úteis e raras, são suscetíveis de apropriação e contêm valor econômico". O bitcoin tem valor econômico e pode se encaixar como um bem incorpóreo. Os bens incorpóreos não têm existência tangível e são relativos aos direitos que as pessoas têm sobre as coisas, sobre os produtos do intelecto (DINIZ, 2013), ou seja, são aqueles que têm existência abstrata, mas com valor econômico, como o direito autoral, o crédito, o fundo de comércio etc. Já os corpóreos são os que têm existência física, material e podem ser tocados pelo ser humano. Bens são úteis aos homens, apresentando expressão econômica, e suscetíveis à apropriação, sendo, portanto, materiais e imateriais. Apesar de a Lei não a contemplar com dispositivo específico, a classificaçáo dos bens corpóreos e incorpóreos tem sua importância, já que a relação jurídica pode ter por objeto uma coisa de existência material ou uma coisa de existência abstrata (GONÇALVES, 2011). O bitcoin, nessa classificação, se define nesse ponto como bem imaterial, já que se trata de uma moeda virtual, algo não palpável. Mas o que a Lei deixou de contemplar no passado causa problemas nos dias atuais, como a definição de bitcoin.

Diniz (2013, p. 366) explica as peculiaridades entre bens e coisas: 


\begin{abstract}
Os bens são coisas, porém nem todas as coisas são bens. As coisas são gênero do qual os bens são espécies. As coisas abrangem tudo quanto existe na natureza, exceto a pessoa, mas como "bens" só se consideram as coisas existentes que proporcionam ao homem uma utilidade, sendo suscetíveis de apropriação, constituindo, então, o seu patrimônio.
\end{abstract}

Os bens, sejam eles corpóreos ou incorpóreos, integram o patrimônio de uma pessoa, alcançando as relações jurídicas ativas e passivas das quais a pessoa é titular, mas nele não se incluem as qualidades pessoais, como conhecimento e força de trabalho (GONÇALVES, 2011). Assim, o bitcoin pode ser considerado patrimônio da pessoa, e isso leva a outra questáo: o patrimônio do devedor responde por suas dívidas e, se os bitcoins respondem, então, devem ser algo ou talvez um bem no sentido jurídico. Como Gonçalves (2011, p. 280) explica, "o patrimônio é uma universalidade de direito, unitário e indivisível, que se apresenta como projeção e continuação da personalidade”.

A doutrina classifica os bens com várias distinçôes, e é possível relacionar o bitcoin com a maioria delas. Para Diniz (2013, p. 368), "a classificação vem a ser uma operação lógica que tem por fim facilitar a compreensão de uma instituição jurídica, agrupando as várias espécies de um gênero, para aproximar as que apresentem um elemento comum".

Nessa classificação, temos os bens imóveis e móveis. Os primeiros são aqueles que não podem ser transportados de um lugar para outro sem que sejam destruídos, e os segundos são aqueles que podem ser transportados de um lugar para outro e, ainda, manterem-se intactos (DINIZ, 2013).

O Código Civil, em seu art. 82, diz: "São móveis os bens suscetíveis de movimento próprio, ou de remoção por força alheia, sem alteração da substância ou da destinação econômico-social” (BRASIL, 2002). Nessa definição, temos os móveis semoventes, que são suscetíveis de movimento próprio, como os animais. Os móveis propriamente ditos são os que admitem remoção por força alheia, sem danos, como os objetos inanimados, por exemplo, moedas, títulos da dívida pública, ação de companhias e objetos de uso (GONÇALVES, 2011). O bitcoin apresenta características semelhantes às desses exemplos.

Segundo o art. 83 do Código Civil (BRASIL, 2002), para efeito legal, são considerados móveis: I - as energias que tenham valor econômico - o bitcoin tem valor econômico, e é preciso energia computacional para criá-lo e utilizá-lo, sendo possível, portanto, considerá-lo um bem móvel; II - os direitos reais sobre objetos móveis e as açóes correspondentes; III - os direitos pessoais de caráter patrimonial e respectivas açóes - esses dois incisos também podem ser relacionados com o bitcoin. 
Existem, também, os bens fungíveis e infungíveis. Os primeiros seriam aqueles que podem ser substituídos por outros de mesmas espécie, qualidade e quantidade (BRASIL, 2002). A fungibilidade é característica dos bens móveis, sendo que os bens fungíveis são substituíveis, isso porque são idênticos econômica, social e juridicamente. A característica advém, pois, da natureza das coisas. Todavia, pode resultar também da vontade das partes, uma moeda é um bem fungível, mas para um colecionador pode tornar-se infungível (GONÇALVES, 2011). A fungibilidade é própria dos bens móveis, sendo o resultado da comparação entre duas coisas equivalentes que podem ser substituídas (DINIZ, 2013).

Já os bens infungíveis são aqueles de natureza insubstituível, o que caracteriza mais os bens imóveis. "Sáo infungíveis os que, pela sua qualidade individual, têm um valor especial, não podendo, por isso, ser substituídos sem que isso acarrete uma alteração de seu conteúdo" (DINIZ, 2013). Nesse caso, os bitcoins podem ser considerados bens infungíveis, na medida em que existe uma quantidade exata que será criada ao longo do tempo, sendo que eles não poderão ser substituídos.

$\mathrm{Na}$ sequência, temos os bens consumíveis e inconsumíveis. Os primeiros, conforme o art. 86 do Código Civil, são "os bens móveis cujo uso importa destruição imediata da própria substância, sendo também considerados tais os destinados à alienação" (BRASIL, 2002). Portanto, como explica Diniz (2013, p. 381), "consumíveis são os que terminam logo com o primeiro uso, havendo imediata destruição de sua substância (ex.: alimentos, dinheiro); caso em que se tem a consuntibilidade natural”. Já os bens inconsumíveis, de acordo com Gonçalves (2011, p. 295) são "os bens que podem ser usados continuamente, ou seja, os que permitem utilização contínua, sem destruição da substância [...]”.

Há, também, os bens divisíveis e indivisíveis. O Código Civil, em seu art. 87, descreve: "Bens divisíveis são os que se podem fracionar sem alteração na sua substância, diminuição considerável de valor, ou prejuízo do uso a que se destinam " (BRASIL, 2002). Para Gonçalves (2011, p. 296), "são divisíveis os bens que se podem partir em porçôes reais e distintas, formando cada qual um todo perfeito". Além disso, "os bens naturalmente divisíveis podem tornar-se indivisíveis por determinaçáo da lei ou por vontade das partes” (BRASIL, 2002).

Os bens indivisíveis por natureza são aqueles que não podem ser partidos sem alteração na sua substância e no seu valor, por exemplo, um quadro, que, quando partido, perde sua integridade e seu valor (DINIZ, 2013). Já os bens indivisíveis por determinação legal são aqueles cujo fracionamento é expressamente impedido por lei, como no caso das servidóes prediais (GONÇALVES, 2011). Por fim, há o bem indivisível por vontade das partes, em que um acordo tornará a coisa comum indivisa por prazo não maior que cinco anos, passível de prorrogação 
(GONÇALVES, 2011). O bitcoin é, por natureza, indivisível, já que, uma vez dividido, ocorre alteraçáo em seu valor. No entanto, isso náo significa que ele não pode ser utilizado como um bem, já que não interfere no propósito de seu funcionamento, o que ocorre é que quando dividido em dois, por exemplo, perde metade de seu valor, mas ainda assim pode continuar sendo utilizado em transaçóes.

Continuando, temos os bens singulares e coletivos. De acordo com o art. 89 do Código Civil, "são singulares os bens que, embora reunidos, se consideram de per si, independentemente dos demais” (BRASIL, 2002). Bens singulares podem ser divididos em simples ou compostos. "Simples seriam as coisas que formarem um todo homogêneo, cujas partes componentes estariam unidas em virtude da própria natureza ou ação humana, sem reclamar quaisquer regulamentaçôes especiais por norma jurídica”, Diniz dá como exemplo de bens simples uma pedra, folha de papel e um cavalo. Já "as coisas compostas seriam aquelas cujas partes heterogêneas fossem ligadas pelo engenho humano, caso em que haveria objetos independentes unidos num só todo sem desaparecer a condição jurídica de cada parte". Como exemplo disso Diniz usa materiais de construção que estão ligados na edificação de uma casa (DINIZ, 2013, p. 385).

No Código Civil, o art. 90 reza que

[...] constitui universalidade de fato a pluralidade de bens singulares que, pertinentes à mesma pessoa, tenham destinação unitária.

Parágrafo único. Os bens que formam essa universalidade podem ser objeto de relaçōes jurídicas próprias (BRASIL, 2002).

Disso, é possível concluir que um bitcoin pode muito bem se encaixar nessa definição, já que uma pessoa física ou jurídica pode ter um ou vários bitcoins, que formam essa universalidade, e podem, também, ser objeto de relaçóes jurídicas. Por sua vez, o art. 91 do referido dispositivo legal destaca: "Constitui universalidade de direito o complexo de relaçóes jurídicas, de uma pessoa, dotadas de valor econômico" (BRASIL, 2002). Esse artigo trata da universalidade como o patrimônio, a herança, o fundo de comércio (GONÇALVES, 2011) e - por que não dizer? - o próprio bitcoin, já que não é necessário que constem objetos materiais, contendo apenas direitos e obrigaçóes que fazem parte das coisas incorpóreas (DINIZ, 2013).

Há, ainda, os bens principais e acessórios: "Principal é o bem que existe sobre si, abstrata ou concretamente; o acessório, aquele cuja existência supóe a do principal” (BRASIL, 2002). Portanto, o bem principal é aquele cuja existência 
é própria, autônoma, é aquele que existe por si mesmo, ao passo que, no caso do bem acessório, para existir juridicamente, depende de um bem principal (GONÇALVES, 2011; DINIZ, 2013). O bitcoin seria, então, indubitavelmente, o principal.

Ainda sobre os bens acessórios, destaca-se que estes são divididos nas seguintes classes: produtos, frutos, pertenças e benfeitorias. Os produtos são as utilidades que se podem retirar da coisa, o que lhe altera a substância e diminui a quantidade até o esgotamento, na medida em que não é capaz de reproduzir-se periodicamente (GONÇALVES, 2011; DINIZ; 2013).

Quanto aos frutos, segundo Gonçalves (2011, p. 303), trata-se das "utilidades que uma coisa periodicamente produz. Nascem e renascem da coisa, sem acarretar-lhe a destruiçấo no todo ou em parte". Ainda de acordo com o autor, eles podem ser naturais, que se desenvolvem e se renovam periodicamente, como os frutos de uma árvore; industriais, que surgem pela mão do homem, na indústria ou na natureza; e civis, que são os rendimentos produzidos pela coisa em virtude de sua utilização, como os juros e aluguéis. Portanto, pode-se dizer que os bitcoins são frutos, já que provêm da mineração computacional que periodicamente os produz, nascendo e renascendo sem causar a destruiçâo da tecnologia que os produz. Conforme Gonçalves (2011, p. 302), "produtos, quando são utilidades provenientes de uma riqueza posta em atividade econômica, seguem a natureza de frutos" - no contexto dos bitcoins, trata-se da utilidade proveniente de uma riqueza posta na atividade econômica, sendo derivado de um fruto da atividade computacional. Além do mais, o art. 1.232 do Código Civil diz: "Os frutos e mais produtos da coisa pertencem, ainda quando separados, ao seu proprietário, salvo se, por preceito jurídico especial, couberem a outrem" (BRASIL, 2002).

As pertenças, por sua vez, são "os bens que, não constituindo partes integrantes, se destinam, de modo duradouro, ao uso, ao serviço ou ao aformoseamento de outro" (BRASIL, 2002), ao passo que as benfeitorias, de acordo com o art. 96 do Código Civil, podem ser voluptuárias, úteis ou necessárias:

\footnotetext{
$\$ 1$ o São voluptuárias as de mero deleite ou recreio, que não aumentam o uso habitual do bem, ainda que o tornem mais agradável, ou seja, de elevado valor.

$\$ 2$ o São úteis as que aumentam ou facilitam o uso do bem.

$\$ 3^{\circ}$ São necessárias as que têm por fim conservar o bem ou evitar que se deteriore (BRASIL, 2002).
}

Tanto as pertenças como as benfeitorias são tipos de bens pertencentes à categoria dos acessórios, mas esses tipos de bens não se enquadram nas características dos bitcoins. 
O Código Civil menciona, também, os bens públicos:

Art. 98. São públicos os bens do domínio nacional pertencentes às pessoas jurídicas de direito público interno; todos os outros são particulares, seja qual for a pessoa a que pertencerem.

Art. 99. São bens públicos:

I - os de uso comum do povo, tais como rios, mares, estradas, ruas e praças;

II - os de uso especial, tais como edifícios ou terrenos destinados a serviço ou estabelecimento da administração federal, estadual, territorial ou municipal, inclusive os de suas autarquias;

III - os dominicais, que constituem o patrimônio das pessoas jurídicas de direito público, como objeto de direito pessoal, ou real, de cada uma dessas entidades.

Por fim, temos os bens relativos à possibilidade de serem ou não comercializados. A palavra comércio é empregada no sentido jurídico, significando a possibilidade de compra e venda e a liberdade para a movimentação dos bens. Os produtos que estáo no comércio são passíveis de compra, venda, troca, doação, aluguel e empréstimo (GONÇALVES, 2011). Os bens que podem ser transmitidos, conforme Diniz (2013) explica, são aqueles que estão livres de quaisquer restriçóes que venham a impossibilitar sua transferência ou apropriação, sendo possível, entáo, passar - gratuita ou onerosamente - de um patrimônio para outro, seja em função de sua natureza ou por disposição legal". Portanto, se o bitcoin for considerado um bem, ele poderá ser transmitido de pessoa para pessoa sem quaisquer restriçóes.

\section{Commodity}

O bitcoin pode ser considerado uma commodity, que, na traduçáo para o português, significa mercadoria. As commodities são elementos importantes para o mundo da economia, referindo-se a determinado bem ou produto de origem primária, comercializado nas bolsas de mercadorias e valores, apresentando grande valor comercial, estratégico e de referência (PENA, 2018).

Como o bitcoin pode ser considerado um bem, ele também pode ser considerado uma commodity, na medida em que é comercializado em mercados de criptomoedas. As commodities são produtos que influenciam o comportamento de determinados setores da economia, isso porque a oscilação em seus preços influencia outras atividades, como a indústria. Então, quando algo é considerado uma commodity, esse bem passa a ter seu preço gerido não pelo valor estipulado na 
produção, mas, sim, por sua cotação no mercado (PENA, 2018).

Assim, o preço do bitcoin é determinado pelo mercado mundial como uma consequência da oferta e da demanda, já que existem mercados específicos de compra e venda de bitcoin, como o Mercado Bitcoin, no caso do Brasil.

As commodities são importantes, também, por causa do desempenho da economia de um país. Algumas economias, sobretudo as de países subdesenvolvidos, dependem muito de uma cotação elevada nas commodities e, quando existe uma crise conjuntural e estrutural, esses países se abalam, uma vez que as exportaçóes caem e a economia local entra em colapso (PENA, 2018). É o caso da crise que aconteceu na Venezuela, país que depende de commodities como o petróleo, onde o Governo recorreu às criptomoedas para contornar sançóes e tentar combater a hiperinflação que assola a economia (RIGGS, 2018).

Assim, os bitcoins apresentam características de commodities, pois, conforme Teweles, Harlow e Stone (1983, p. 17), commodities "são produtos cujos preços estão sujeitos à grandes altas e baixas, motivadas pela lei da oferta e procura, cujo equilíbrio é afetado por numerosos fatores, como quebra de safra, supersafra, recessão mundial, taxa de juros, intervenção governamental".

Pode-se deduzir, então, que qualquer coisa pode servir como dinheiro, contanto que seja valorada pelos indivíduos, como uma unidade de bitcoin, que, apesar de incorpóreo, é empregado como meio de troca e dinheiro propriamente dito (ULRICH, 2014).

\section{Regulação e legislaçáo}

No Brasil, o bitcoin e as outras criptomoedas ainda não têm seu uso regulamentado. Conforme Ulrich (2014), as leis e regulaçôes atuais não preveem uma tecnologia como o bitcoin, pois esse tem propriedades de pagamento eletrônico, moeda, commodity, entre outros, o que, certamente, estaria sujeito a diversos órgãos reguladores. "Isso ocorre porque o bitcoin não se encaixa em definiçôes regulamentares existentes de moeda ou outros instrumentos financeiros ou instituiçôes, tornando complexo saber quais leis se aplicam a ele e de que forma" (ULRICH, 2014, p. 33).

Existe no Brasil um projeto de Lei (PL n. 2.303/2015) que defende a regulamentação das criptomoedas. Contudo, a dificuldade de concretização da legislação do bitcoin no Brasil está ligada de maneira visceral à ausência clara da definição da natureza do bitcoin em terras brasileiras. Institutos inovadores como o bitcoin tendem a trazer este tipo de incerteza, uma vez que se colocam além de conceitos jurídicos previamente estabelecidos. Quando se avaliam as criptomoedas em 
um sentido amplo, elas são negociadas diariamente em nível mundial sendo a compra e venda feita diretamente entre os usuários, o que deixaria uma possível regulamentação sem muita eficácia no sentido de tentar abranger todo potencial do bitcoin. O desafio consiste em regulamentar as moedas e classificá-las como "arranjos de pagamento", sob a supervisão do Banco Central (LONDRES, 2017).

Esse projeto de lei ainda não foi aprovado, mas "a comissão de Direito Financeiro do Instituto dos Advogados Brasileiros deu parecer favorável ao uso de moedas virtuais e programas de milhagem aérea em pagamentos, sob a supervisão do Banco Central” (IAB DÁ PARECER..., 2018).

Conforme o relator José Enrique Teixeira Reinoso "o projeto de lei aborda a questão de extrema relevância para o mercado atual, é constitucional, e não implica, a priori, em aumento de despesa pública”. Segundo ele, a Receita Federal informou que, em 2017, a movimentação de moedas virtuais chegou a $\mathrm{R} \$ 8,3$ bilhóes (IAB DÁ PARECER..., 2018).

Reinoso acredita tratar-se de um projeto de lei de extrema relevância, uma vez que o tema é de repercussão mundial, tendo como expressôes de sua demanda a circulaçáo do bitcoin, do ether e do litecoin, bem como os programas de milhagens. A moeda virtual é um meio de troca possível, cuja função primordial seria evitar custos com instituiçôes financeiras (IAB DÁ PARECER..., 2018).

Em outros países, a situaçáo é diversa, como na China e no Equador, onde a legislação proíbe expressamente as criptomoedas. Já nos Estados Unidos, há uma regulamentação permissiva e, na Alemanha, o bitcoin foi reconhecido como meio de pagamento, o que criou um precedente importante para que outros países da Europa se posicionem positivamente a respeito das criptomoedas. Nesse sentido, a proibição não é o caminho que deve ser tomado pela maior parte das naçóes (LEGISLAÇÃO BITCOIN..., 2018).

No Brasil, ainda existem muitas dúvidas sobre investimentos em criptomoedas. Para saná-las, a Comissão de Valores Mobiliários (CVM, 2014) manifestou-se dizendo:

Como sabido, tanto no Brasil quanto em outras jurisdiçóes ainda tem-se discutido a natureza jurídica e econômica dessas modalidades de investimento, sem que tenha, em especial no mercado e regulação domésticos, se chegado a uma conclusão sobre tal conceituação. Assim e baseado em dita indefinição, a interpretação desta área técnica é a de que as criptomoedas não podem ser qualificadas como ativos financeiros, para os efeitos do disposto no artigo 2º, V, da instrução CVM no 555/14, e por essa razão, sua aquisiçấo direta pelos fundos de investimento ali regulados não é permitida. 
A CVM continua afirmando que existem discussóes sobre o investimento em criptomoedas, mas que se encontram em patamar ainda bastante inicial e que convivem com o PL n. 2.303/2015, que pode vir a impedir, restringir ou mesmo criminalizar a negociação de criptomoedas. Além disso, "no entendimento da área técnica é inegável que, em relação a tal investimento, há ainda muitos outros riscos associados à sua própria natureza $[\ldots]$ ou mesmo ligados à legalidade futura de sua aquisição ou negociação" (CVM, 2014).

Finalizando, a CVM (2014) informa que "todas as variáveis vêm sendo levadas em consideração na avaliação da possibilidade de constituição e estruturação do investimento indireto em criptomoedas, sem que se tenha chegado, ainda, à uma conclusão a respeito dessa possibilidade". Por fim, julgam conveniente que administradores e gestores de fundos de investimentos aguardem a superintendência se manifestar sobre o tema de maneira mais conclusiva, para que estruturem o investimento indireto em criptomoedas.

Nota-se, com isso, que ainda existe uma grande insegurança jurídica gerada pela falta de uma regulamentaçáo que defina que caminho os fundos de investimentos, empresas e pessoas físicas devem tomar para utilizar criptomoedas como o bitcoin. Porém, essa ausência não deve tardar a ser preenchida, já que legisladores estão se movimentando na direçáo de regulamentar o uso das criptomoedas no Brasil.

\section{Conclusáo}

Em um primeiro momento, é fácil associar o bitcoin a uma moeda, na medida em que aquele é comumente associado a uma moeda eletrônica, sendo chamado de moeda digital, moeda virtual ou criptomoeda. Essa associação não está equivocada, já que ao longo deste artigo se encontram indícios de que o bitcoin pode realmente ser uma moeda, por apresentar, entre outras, as seguintes características: ser intermediária de trocas, unidade de valor e reserva de valor. Desses três pontos, o único que se mostrou mais frágil é o da reserva de valores, já que nos últimos anos o bitcoin apresentou grande volatilidade. A partir do momento em que o bitcoin alcançar uma estabilidade, poderá, talvez, ser considerado uma moeda, uma vez que está sendo utilizado como forma de pagamento desde seu surgimento.

Apesar dos indicativos, o bitcoin ainda não é garantido pelo Estado e talvez ainda esteja longe disso, o que também impede sua aceitação oficial enquanto moeda.

Ainda que pareça uma moeda, o bitcoin também acabou apresentando caraterísticas de um bem, tendo como referência para essa conclusão, o ordenamento 
jurídico brasileiro, por meio de análise legislativa e doutrinária.

Considerando o bitcoin um bem imaterial, ele se encaixa na definição de ser algo que tem valor econômico e que pode servir de objeto a uma relação jurídica. Pode, também, ser considerado algo útil, raro e suscetível à apropriação, apresentando valor econômico.

Além do mais, o bitcoin pode ser considerado um bem móvel. Tal raciocínio se sustenta em seu valor econômico e na energia computacional que é necessária para o bitcoin existir.

Os bitcoins podem, também, ser considerados commodities, sendo comercializados em mercados de criptomoedas, tendo seu valor regido por cotaçóes de mercado e estando sujeitos a grandes altas e baixas, o que afeta seu equilíbrio, mas acaba atraindo investidores.

Por fim, a regulamentação no Brasil parece estar a caminho, e como já existe um projeto de lei que aborda esse assunto, é questáo de tempo para que comecem a ser preenchidas as lacunas jurídicas em torno do bitcoin, pois a regulamentaçáo é relevante para os avanços tecnológicos na área das criptomoedas, bem como para outras empresas ligadas à tecnologia do blockchain.

\section{Referências}

ANTONOPOULOS, A. Mastering Bitcoin. Newton: O’Reilly, 2016.

ASSAF NETO, A. Mercado financeiro. 4. ed. São Paulo: Atlas, 2001.

BERCHIELLI, F. O. Economia monetária. São Paulo: Saraiva, 2000.

BRASIL. Lei n.10.406, de 10 de jan.de 2002. Código Civil, Brasília, DF, jan. 2002.

CVM - COMISSÃO DE VALORES MOBILIÁRIOS. Instrução CVM 555, de 17 de dezembro de 2014. Dispóe sobre a constituição, a administração, o funcionamento e a divulgação das informaçôes dos fundos de investimento. Disponível em: http://www.cvm.gov.br/legislacao/instrucoes/inst555.html. Acesso em: 21 jan. 2019.

DINIZ, M. H. Curso de Direito Civil Brasileiro. 30. ed. São Paulo: Saraiva, 2013. GONÇALVES, C. R. Direito Civil Brasileiro. 9. ed. São Paulo: Saraiva, 2011.

IAB DÁ PARECER favorável a uso de moedas virtuais e milhagens em pagamentos. Consultor Jurídico, 21 dez. 2018. Disponível em: https://www.conjur.com. br/2018-dez-21/iab-parecer-favoravel-uso-moedas-virtuais-pagamentos. Acesso em: 20 jan. 2019. 
LEGISLAÇĀO BITCOIN: como aplicar em Bitcoin dentro da Lei? Bitcointrade, 20 ago. 2018. Disponível em: http://blog.bitcointrade.com.br/regulamentacao-do-bitcoin-atualmente-ele-esta-autorizado-no-brasil/. Acesso em: 9 jan. 2019.

LONDRES, M. Câmara avança na regulamentação do 'Bitcoin' no Brasil. Coluna do Fraga, 2017. Disponível em: https://noticias.r7.com/prisma/coluna-do-fraga/ camara-avanca-na-regulamentacao-do-bitcoin-no-brasil-02012018. Acesso em: 9 jan. 2019.

MARINHO, H. Politica monetária no Brasil: da teoria à prática. 4. ed. Rio de Janeiro: Campus, 1996.

MEDEIROS, E. Bitcoin: entenda o que é e por onde começar. [S.I.]: [s.n.], 2017.

PENA, R. A. Commodities. Mundo Educação, 2018. Disponível em: https:// mundoeducacao.bol.uol.com.br/geografia/commodities.htm. Acesso em: 23 ago. 2018.

RIGGS, W. Após destruir dinheiro nacional, governo da Venezuela adota criptomoeda como moeda oficial. Portal do Bitcoin, 19 ago. 2018. Disponível em: https://portaldobitcoin.com/apos-destruir-dinheiro-nacional-governo-da-venezuela-adota-criptomoeda-como-moeda-oficial/. Acesso em: 23 ago. 2018.

ROSSETTI, J. P. Economia monetária. 9. ed. São Paulo: Atlas, 2011.

SANT'ANA, J. A. Economia monetária: a moeda em uma economia globalizada. Brasília, DF: UnB, 1997.

STANFORD, J. D. Moedas, bancos e atividade econômica. São Paulo: Atlas, 1981.

TEWELES, R. J.; HARLOW, C. V.; STONE, H. L. O jogo de commodities: quem ganha? Quem perde? Por quê? 1. ed. São Paulo: Brasimex, 1983.

TOLOTTI, R. Como declarar bitcoin e outras criptomoedas no Imposto de Renda. InfoMoney, 23 fev. 2018. Disponível em: https://www.infomoney.com. $\mathrm{br} / \mathrm{mercados} /$ bitcoin/noticia/7283840/como-declarar-bitcoin-e-outras-criptomoedas-no-imposto-de-renda. Acesso em: 14 jan. 2019.

ULRICH, F. Bitcoin: a moeda na era digital. São Paulo: Mises Brasil, 2014. 